Historic, archived document

Do not assume content reflects current scientific knowledge, policies, or practices. 



\section{UNITED STATES DEPARTMENT OF AGRICULTURE}

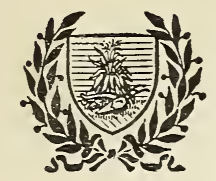

\section{BULLETIN No. 888}

Contribution from the Bureau of Entomology

L. O. HOWARD, Chief

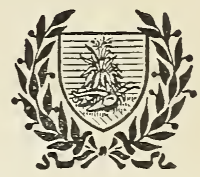

Washington, D. C.

PROFESSIONAL PAPER

October 13,1920

\section{RESULTS OF EXPERIMENTS WITH MISCELLANE- OUS SUBSTANCES AGAINST CHICKEN LICE AND THE DOG FLEA:}

By W. S. Аввотт, Entomologist, Enforcement Insecticide Act.

\section{CONTENTS.}

\begin{tabular}{|c|c|c|c|}
\hline \multicolumn{2}{|c|}{ ge. } & \multicolumn{2}{|c|}{ Page. } \\
\hline Introduction... & 1 & The dog flea. & 9 \\
\hline Chicken lice.............. & 2 & Methods of testing. & 9 \\
\hline Methods of testing $\ldots \ldots \ldots \ldots \ldots \ldots \ldots$ & 2 & Pyrethrum powder.. & 9 \\
\hline Oil preparations used as sprays .......... & 2 & Naphthalene.......... & 10 \\
\hline Oil preparations used as fumigants...... & 3 & Chicken-lice powders. & 11 \\
\hline Oil preparations applied to roosts, drop- & & Miscellaneous powdered mixtures........ & 11 \\
\hline ping boards, and interior of chicken & & Miscellaneous powdered materials ....... & 11 \\
\hline houses ............. & 4 & Tobacco powders .......... & 12 \\
\hline Mercurial ointment ........... & 4 & Sprays & 12 \\
\hline Chicken-lice powders.. & 5 & Washes. & 13 \\
\hline Miscellaneous preparations... & 5 & Dips ........ & 13 \\
\hline Pyrethrum powder $\ldots \ldots \ldots \ldots \ldots \ldots \ldots$ & 5 & Liquids used as fumigants. & 13 \\
\hline Tobacco powders & 6 & Summary...$\ldots \ldots \ldots \ldots \ldots \ldots$ & 14 \\
\hline Naphthalene........................ & 6 & Recommendations ............... & 15 \\
\hline Miscellaneous powdered materials.. & 6 & & \\
\hline Summary...$\ldots \ldots \ldots \ldots \ldots \ldots$ & 7 & - & \\
\hline & & & \\
\hline
\end{tabular}

\section{INTRODUCTION.}

In connection with the enforcement of the insecticide act of 1910 a large number of proprietary insecticides and the ingredients entering into their composition have been tested against chicken lice and the dog flea. These experiments have been briefly summarized and form the basis of this bulletin.

This work was done at the Insecticide Board's testing laboratory, located at Vienna, Va., which is under the supervision of Dr. A. L. Quaintance, of the Bureau of Entomology, and under the direct charge of Mr. E. W. Scott. ${ }^{1}$

Assistance was also rendered at different times by Messrs. W. F. Turner, J. F. Zimmer, and W. B. Sill. 


\section{CHICKEN LICE.}

Several species of lice were present on the fowls used in these tests, viz, the body louse, Menopon biseriatum Piaget; the shaft louse, Menopon pallidum Nitzsch; and the large hen louse, Goniocotes abdominalis Piaget. The most abundant species were the body louse and the shait louse and these were always present in large numbers.

METHODS OF TESTING.

Three general methods of testing were employed: First, treating the individual fowls by dusting, spraying, dipping, or the "vent treatment" (see Mercurial ointment, p. 4-5); second, fumigation by confining the fowls in a box which had been painted or sprayed inside with the material to be tested; and, third, painting or spraying the roosts and dropping boards or the whole interior of the house.

Dusting.--Two persons worked together in dusting, one holding the bird and spreading the feathers, while the other applied the powder with a shaker or small hand dust gun. Except where noted the powders were well rubbed into the feathers.

Spraying.-The liquids were applied with a hand sprayer and were also well rubbed in, unless otherwise noted.

Dipping.-In the dipping tests the birds were held in the solution for from one-half to one minute and the head was submerged for about a second, once or twice.

Vent treatment.-In these tests the materials were thoroughly rubbed into the skin of the fowl around, or just below, the vent.

Fumigation.-In these tests the liquids, largely hydrocarbon oil mixtures, were applied to the bottom or bottom and sides of a box and the infested fowls were then placed in the box, which was covered with two or three thicknesses of burlap. The birds were left in the box for from 5 minutes to 3 hours.

Painting the house.-For these experiments the roosts and dropping boards, and often the whole interior of the chicken house, were painted or sprayed a short time before the birds went to roost, and the house remained tightly closed for that night.

\section{OIL PREPaRations USED AS SPRAYS.}

Tests with 22 different mixtures containing hydrocarbon oils, phenols, nitrobenzol, coal tar, wood-tar distillate, pyridine bases, and soaps showed that such preparations will kill practically all of the lice if lightly applied. The emulsions at dilutions not greater than 1 to 100 are also effective, but a dilution of 1 to 250 is of no value. Dipping tests indicated that these preparations are effective at about the same dilution. When dipped in or rubbed with the undiluted oils the fowls as well as the lice were killed. In two tests fowls dipped 
in lime-sulphur concentrate ( $33^{\circ}$ Baumé), diluted 1 part to 14 parts of water, were completely freed from lice.

The use of these mixtures can not be highly recommended for the following reasons: Too heary an application may kill or seriously injure the treated birds; the plumage is left in a soiled and dirty condition and the oils retained on the feathers may have an injurious effect on the eggs in the case of sitting hens. Unless the dipping or spraying is done on a warm, clear day there is danger that the fowls may become chilled.

\section{OIL PREPARATIONS USED AS FUMIGANTS.}

Table I shows the results of tests with oil mixtures used as fumigants against chicken lice.

TABLE I.-Results of tests with oil preparations used as fumigants against chicken lice. Two or more fowls confined in a sprayed or painted box for each test.

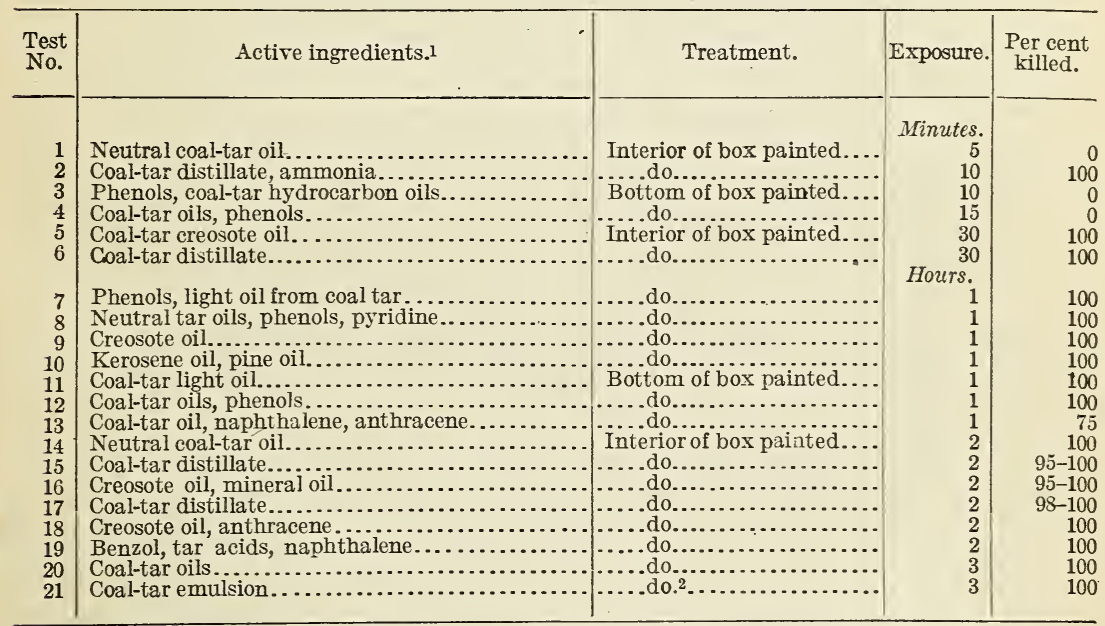

1 An active ingredient is one that is effective against chicken lice when used at a proper dilution. 2 Diluted 1 to 25.

This table shows that almost all of these preparations were very effective against lice when the fumigation was continued for not less than 30 minutes. If only the bottom of the box was treated, an exposure of 10 or 15 minutes failed to kill any lice but when the whole interior of the box was painted or sprayed a fumigation of 10 minutes was effective. An exposure of 5 minutes under the latter conditions was of no value.

Although effective, this method of treatment can not be recommended because of the injurious effect on the fowls. While no chickens were actually killed in these tests they were all more or less affected by the treatment as was shown by their very laborious 
breathing and general weakness when released from the box. These effects passed away in 5 or 10 minutes, and in no case was any permanent injury noted. This treatment also left the feathers somewhat soiled, as the fowls in their struggles came in contact with the freshly treated surfaces of the box.

In two tests where the bottom of the nest box used by a sitting hen was painted with this type of preparation it was noted that from 95 to 100 per cent of the lice on the hen were killed or repelled and the eggs apparently were not injured. While sufficient tests were not made to determine the practicability of this treatment for the control of lice on sitting hens, it appears to be worthy of further investigation.

\section{OIL PREPARATIONS APPLIED TO ROOSTS, DROPPING BOARDS, AND INTERIOR OF CHICKEN HOUSES.}

There have been many advocates of the theory that chicken lice can be killed by painting the roosts and dropping boards or the whole interior of the poultry house with various oil mixtures, the idea being that the vapors or gases arising from these paints would penetrate the feathers of the roosting fowls and kill the lice. This method was given a very extensive trial and not one of the 42 different preparations tested was found to be of any value. These preparations contained one or more of the following ingredients: Phenols, tar oils, hydrocarbon oils, creosote oil, carbon disulphid, wood-tar distillate, benzol, nitrobenzene, naphthalene, anthracene oil, and pyridine and were of the same general character as those discussed in Table I (p. 3).

In these experiments the roosts and dropping boards or the whole interior of the house were thoroughly painted or sprayed just before the fowls went to roost and all doors, windows, and ventilators were closed during the first night. Five badly infested fowls were used in each test and at the end of one week examination was made for living lice. Although an occasional dead louse was found on the dropping boards, in no case was the treatment of any practical value. Since many of these same preparations were found to be effective when used as fumigants in small boxes, it is apparent that the ineffectiveness of this house treatment is due to the fact that the fumes do not become concentrated enough to kill the lice. Tests were also made with lime-sulphur applied in the same way and this also was found to be of no value.

\section{MERCURIAL OINTMENT.}

Five proprietary and two homemade mercurial ointments were tested and found to kill from 95 to 100 per cent of the body lice present. These ointments contained from 3 to 26 per cent of mercury mixed with lard, vaseline, paraffin, or some semisolid of this type 
and were applied by rubbing a piece about the size of a pea well into the skin around or below the vent of the infested fowls. This method of treatment has been thoroughly tested by G. H. Lamson and J. A. Manter. ${ }^{2}$ The active ingredient here is the mercury, since paraffin or vaseline applied in the same manner is of no value.

\section{CHICKEN-LICE POWDERS.}

Forty-five of the common proprietary powders generally sold as "Lice Powder," "Lice Killer," "Lice Exterminator," etc., were tested and, with a few exceptions, were found to be effective if thoroughly applied. These powders are all of the same general type and contain one or more of the following active ingredients: Naphthalene, nicotine, sulphur, pyrethrum, or phenols, and are mixed with lime, sand, talc, fuller's earth, or diatomaceous earth as a filler or carrier. Most of these active ingredients have been tested separately, and the minimum amounts that will be completely effective when very carefully and thoroughly applied by experienced persons are as follows: Naphthalene 10 per cent, nicotine 0.75 per cent, sulphur 20 per cent(?), pyrethrum 5 per cent, phenols 15 per cent (?).

In some of these powders the actual percentage of one or even all of the active ingredients fell below the minima given above, but the combined action of all of the active ingredients was sufficient to make the preparation effective.

\section{MISCELLANEOUS PREPARATIONS.}

In two tests, in which powders containing nicotine, naphthalene, and sulphur were added to the dust baths furnished to lousy hens, 95 to 100 per cent of the lice were killed. This method of treatment is not, however, a very practical one, since all fowls do not dust themselves and the few that do not wiil eventually reinfest the whole flock.

Nicotine, if used at a reasonable strength, was found to be effective as a dip or spray.

Lime-sulphur added to the drinking water (1 teaspoonful to a gallon), and a powder composed of sulphur, salt, sodium carbonate, naphthalene, charcoal, and lime, which was given with the food, were found to be absolutely without any effect on the lice.

\section{PYRETHRUM POWDER. ${ }^{3}$}

In a series of 12 tests pyrethrum powder (insect powder, Dalmatian insect powder, or Persian insect powder) was found to be very effective, killing all of the lice within 24 hours. In dilution tests it was found that a powder containing 5 per cent of pyrethrum was effective if very thoroughly and carefully applied.

2 Lamson, G. H., jr., and Manter, J. A. Some lice and mites of the hen. Storrs Agr. Exp. Sta., Storrs, Conn., Bul. 86. 1916.

3 Powdered flower heads of Pyrethrum cincrariafolium and P. roseum. 
Powdered pyrethrum stems were carefully tested and proved to be of no value against these insects.

\section{TOBACCO POWDERS.}

A series of 27 tobacco powders ranging from 0.025 to 5.26 per cent nicotine was thoroughly tested against chicken lice and the results of these tests may be summarized briefly as follows: From 0.75 to 1 per cent of nicotine is of some value against these lice, but 1.15 or 1.25 per cent is as low as can be relied on for the best results, and even then the powder must be very freely and carefully applied.

\section{NAPHTHALENE.}

A large amount of work has been done with naphthalene in various forms as a remedy against chicken lice. ${ }^{4}$ The data gathered show that powders containing 20 per cent or more are very effective but can not be generally recommended, since as little naphthalene as 10 per cent may temporarily injure the dusted fowls and 60 per cent may kill them if the powder is well rubbed in.

Finely powdered naphthalene was found to kill from 20 to 100 per cent of the lice when sifted over the backs of fowls after they had gone to roost at night. While in no case were the lice completely eradicated by this treatment, and it is not as effective as the dusting of the individual birds, it is considered that this method may be of some value.

Numerous tests with naphthalene (6.49 to 100 per cent) nest eggs, which have been frequently sold as remedies for lice on laying and sitting hens, proved that they were of absolutely no value. When these eggs were placed in nests used by laying hens and allowed to remain from 1 to $3 \frac{1}{2}$ weeks, no effect could be noted on the lice and in several cases they were more abundant at the close of the experiment than at the beginning. They were useless against lice on sitting hens either when placed under the hen for two hours each week (as recommended), or when allowed to remain under the hen for the entire incubation period. Under the latter conditions, especially during hot weather, the hens were frequently driven from the nest and some of them were made very sick for two or three days. There was also considerable evidence to show that the eggs were seriously injured by the naphthalene, but not enough data are available to prove this absolutely.

\section{MISCELLANEOUS POWDERED SUBSTANCES.}

The following is a list of powdered substances that were found to be effective against chicken lice when used as dusts: Arsenic trioxid, barium fluorid, barium tetrasulphid, ${ }^{5}$ borax, boric acid, cloves, naph-

4 Abbott, W. S. Naphthalene v. Chicken lice. In Jour. Econ. Ent., v. 12, no. 5, p. 397-402. 1919.

5 Did not kill all the lice. 
thalene, paradichlorobenzene, sabadilla seeds, sassafras bark, sodium fluorid, flour of sulphur, and refined sulphur. Only a few of these materials can, however, be considered of any practical value in the control of chicken lice. Arsenic trioxid is too poisonous; barium fluorid, cloves, sabadilla seeds, and paradichlorobenzene are too expensive, or not readily available in large quantities; naphthalene is dangerous if applied too freely, ${ }^{6}$ and barium tetrasulphid does not kill all of the lice. ${ }^{6}$

Sodium fluorid, which was first tested in 1915 and found to be very effective, is the most practical remedy given in this list. This material has been tested on a practical scale by F. C. Bishopp and $\mathrm{H}$. P. Wood ${ }^{7}$ and is recommended by them as the best insecticide for the control of this pest.

The materials listed below were found to be of no value against chicken lice:

Angelica root.

Calcium carbonate.

Calcium fluorid.

Calcium hydroxid.

Calcium oxid.

Calcium sulphate.

Colocynth pulp.

Diatomaceous earth.

Dolomitic lime.

Eucalyptus leaves.

Ferrous oxid.

Flour, wheat.

Gypsum.

Hellebore.
Lime, air slaked.
Lime, water slaked.
Magnesium carbonate.
Magnesium oxid.
Magnesium silicate.
Orris root.
Quassia chips.
Road dust.
Silica.
Sodium bicarbonate.
Vermilion.
Yellow ochre.

Hellebore.

Lime, air slaked.

Lime, water slaked.

Magnesium carbonate.

Magnesium oxid.

Magnesium silicate.

rris root.

Quassia chips.

Road dust.

Silica.

Sodium bicarbonate.

Yellow ochre.

The fact that 26 different finely powdered materials- 7 organic $\Rightarrow$ and 19 inorganic-were found to be of no value shows the fallacy of the old idea that any fine powder is effective against chicken lice if dusted into the feathers.

SUMMARY.

1. Oil mixtures were effective when lightly sprayed on the birds. When used as dips or when well rubbed into the feathers the treated fowls were killed. Oil emulsions were effective at a dilution not greater than 1 to 100 .

2. Fumigation with oil preparations, the infested bird being placed in a sprayed or painted box for not less than 30 minutes, was effective. The fowls were somewhat injured by this treatment, but soon recovered.

3. Oil preparations were of no value against chicken lice when painted or sprayed on the roosts, dropping boards, and the whole interior of the chicken house.

\footnotetext{
${ }^{6}$ See page 6.

7 Bishopp, F. C., and Wood, H. P. Mites and lice on poultry. U. S. Department of Agriculture Farmers' Bulletin 801.1917.
} 
4. Mercurial ointment, applied around or just below the vent of the fowl, was very effective, and vaseline and paraffin were of no value when applied in the same way.

5. Forty-five chicken-lice powders containing naphthalene, nicotine, pyrethrum, sulphur, and phenols proved to be effective when the active ingredients were present in the necessary amounts.

6. Powders containing nicotine, naphthalene, and sulphur were effective against chicken lice when added to the dust bath. Limesulphur added to the drinking water and one powder which was mixed with the food had no effect on the lice.

7. Pyrethrum powder was very effective, and pyrethrum stems of no value against chicken lice.

8. Tobacco powders containing not less than 0.75 to 1 per cent of nicotine are of some value but do not kill all of the lice. About 1.5 per cent is required for the best results.

9. A powder containing 10 per cent of naphthalene was effective against these pests but slightly injured the fowls, and 60 per cent killed the birds when well rubbed in. Naphthalene sprinkled over the backs of fowls at roost proved to be of considerable value against chicken lice. Naphthalene nest eggs were of no value against lice and proved injurious to sitting hens.

10. Thirteen miscellaneous powdered materials were tested and found to be effective and 26 ineffective against chicken lice.

\section{RECOMMENDATIONS.}

Since chicken lice breed on the body of the fowl, it is necessary to treat each and every bird in the flock for the control of these pests, and no treatment of the roost, dropping boards, or chicken house can be of any value. ${ }^{8}$

The following insecticides have been found to be very effective:

Mercurial ointment. ${ }^{9}$ - This remedy is prepared by mixing 1 part of mercurial ointment (50 per cent metallic mercury) with 1 or 2 parts of vaseline, lard, or some other carrier of like consistency. A lump of this ointment about the size of a pea is rubbed into the skin just below or around the vent and an equal amount under each wing. A slight reddening of the skin may result, but no permanent injury has been noted.

Sodium fluorid. ${ }^{10}$-This material, used as a dust or as a dip at the rate of 1 ounce commercial or $\frac{3}{4}$ ounce chemically pure sodium fluorid to 1 gallon of water, has been found to be very effective.

Sulphur.-Used freely as a dust, sulphur forms a cheap and very effective lice killer.

8 This house treatment, on the other hand, is absolutely essential for the control of the chicken mite, Derimanyssus gallinæ Redi.

${ }^{9}$ For a full account of experiments with this material see Lamson, G. H., and Manter, J. A., op. cit.

10 See Bishopp, F. C., and Wood, H. P., op. cit. 
Pyrethrum.-Good, fresh pyrethrum powder is one of the best insecticides for the control of lice, but is too expensive for use on a large scale.

\section{THE DOG FLEA. ${ }^{11}$}

METHODS OF TESTING.

The tests of insecticides against the dog flea were made under natural conditions except that the dogs were not allowed to return to the kennels until after the final records had been taken, as the kennels were, at all times, badly infested with fleas. Before each test the dogs were carefully examined to ascertain the degree of infestation and, unless a fairly large number of fleas was found, the animal was not used. After the dogs had been treated they were confined in large wire cages or tied to trees in the open air. Examinations were made at the end of 2,24 , or 48 hours, but no test was closed at the end of 2 hours unless nearly all of the fleas had been killed or repelled. It was considered that a material which had produced no noticeable results in 24 hours was ineffective. The sprays were applied with a hand sprayer, and the dusts with a small powder gun or a tin shaker. Both dusts and sprays were well rubbed in with the hand unless otherwise noted. In testing the washes, the dogs were placed in a tub containing 4 or 5 inches of the wash to be tested and thoroughly scrubbed by means of a sponge or cloth dipped in the liquid. In the dipping tests the animals were immersed for 1 or 2 minutes in the solution until all but the mouth and eyes were covered and the top of the head was well soaked by hand. In every case the materials to be tested were very thoroughly and carefully applied, so that these results represent their maximum value.

The results are given as "per cent killed or repelled," and these figures are, of course, only estimates. In most cases, even when an effective remedy was used, very few dead fleas were found on the dogs at the time of examination, although there is very little evidence that any material, with the possible exception of naphthalene, actually drove the fleas from the dogs without killing them.

\section{PYRETHRUM POWDER.}

Table II gives the results of tests with pyrethrum powder and powdered pyrethrum stems against the dog fleas.

This table shows that pyrethrum powder (insect powder, Dalmatian powder, or Persian insect powder) is very effective but that powdered pyrethrum stems are of no value against the dog flea. It also shows that while 4 or 10 per cent of good pyrethrum is of value, at least 50 per cent should be used in a mixed powder to secure the best results. 
TABLE II.-Results of dusting tests with pyrethrum powders and powdered stems against the dog flea.

\begin{tabular}{|c|c|c|c|c|c|}
\hline \multirow{2}{*}{ Test No. } & \multicolumn{2}{|c|}{ Active ingredients. } & \multirow{2}{*}{ Inert ingredients. } & \multirow{2}{*}{$\begin{array}{l}\text { Number } \\
\text { of dogs } \\
\text { treated. }\end{array}$} & \multirow{2}{*}{$\begin{array}{l}\text { Per cent } \\
\text { of fleas } \\
\text { killed or } \\
\text { repelled. }\end{array}$} \\
\hline & $\begin{array}{c}\text { Per cent } \\
\text { pyrethrum. }\end{array}$ & Miscellaneous. & & & \\
\hline 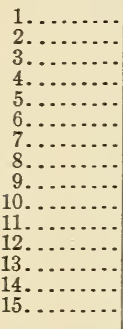 & $\begin{array}{r}4.00 \\
10.00 \\
12.59 \\
18.00 \\
32.63 \\
\text { (?) } 41.00 \\
\text { (?) } 88.00 \\
93.66 \\
100.00 \\
100.00 \\
100.00 \\
100.00 \\
\cdots \\
\hdashline \ldots . . .\end{array}$ & 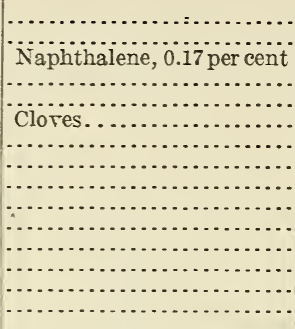 & 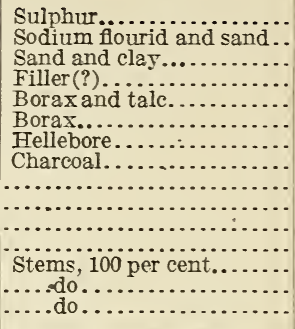 & \begin{tabular}{l|}
2 \\
1 \\
1 \\
2 \\
2 \\
2 \\
2 \\
2 \\
1 \\
2 \\
1 \\
1 \\
2 \\
1 \\
8
\end{tabular} & $\begin{array}{r}50-80 \\
98 \\
30 \\
75-85 \\
15-20 \\
100 \\
100 \\
100 \\
100 \\
100 \\
100 \\
100 \\
0 \\
0 \\
0\end{array}$ \\
\hline
\end{tabular}

The low killing noted in tests Nos. 3 and 5 can be accounted for on the supposition that the pyrethrum in these mixtures had deteriorated since it has been shown ${ }^{12}$ that pyrethrum, exposed to the air, loses practically all of its value in 150 weeks and when kept in sealed glass containers is worthless after $5 \frac{1}{2}$ years.

\section{NAPHTHALENE.}

Table III shows the results of dusting tests with various percentages of naphthalene against the dog flea.

TABLE III.-Results of dusting tests with naphthalene against the dog flea.

\begin{tabular}{|c|c|c|c|c|c|}
\hline Test No. & $\begin{array}{l}\text { Per cent } \\
\text { naphtha- } \\
\text { lene. }\end{array}$ & Inert ingredients. & $\begin{array}{l}\text { Number } \\
\text { of dogs } \\
\text { treated. }\end{array}$ & $\begin{array}{l}\text { Per cent } \\
\text { of fleas } \\
\text { killed or } \\
\text { repelled. }\end{array}$ & Remarks. \\
\hline 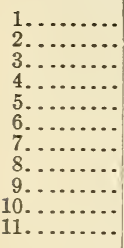 & $\begin{array}{r}1.52 \\
6.48 \\
10.00 \\
12.17 \\
20.00 \\
40.00 \\
50.00 \\
59.21 \\
75.00 \\
100.00 \\
100.00\end{array}$ & 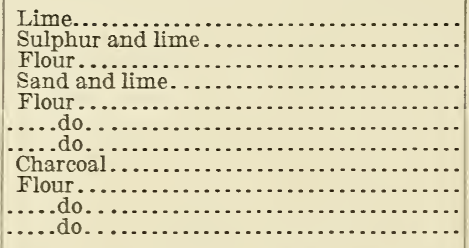 & \begin{tabular}{l|l}
2 & \\
2 & \\
1 & \\
1 & \\
2 & \\
1 & \\
1 & \\
2 & \\
2 & \\
3 & \\
2 &
\end{tabular} & $\begin{array}{r}0 \\
0 \\
0 \\
10-20 \\
0 \\
0 \\
0 \\
50-60 \\
5-10 \\
50 \\
98-100\end{array}$ & $\begin{array}{l}\text { Rubbed in. } \\
\text { Do. } \\
\text { Not rubbed in. } \\
\text { Rubbed in. } \\
\text { Not rubbed in. } \\
\text { Do. } \\
\text { Do. } \\
\text { Rubbed in. } \\
\text { Not rubbed in. } \\
\text { Do. } \\
\text { Rubbed in. }\end{array}$ \\
\hline
\end{tabular}

Table III shows that naphthalene, which frequently has been recommended against dog fleas, is effective, providing it is thoroughly rubbed into the hair and that powders containing 75 per cent or less are of little or no value. The table also shows very clearly the necessity of working the powder well down into the hair, since a powder containing 59 per cent (test 8) which was well rubbed in was as effective as pure naphthalene (test 10) which was only dusted over

12 Abbott, W. S. A study of the effect of storage, heat, and moisture on pyrethrum. U.S. Department of Agriculture Bulletin 771. 1919. 
the dogs. In order to be of any value this material must be finely pulverized, since, in the form that it is usually found on the market (moth balls or rather coarse flakes and crystals), it can not be well worked down to the skin, especially in the case of long-haired dogs. This material seems to act somewhat as a repellent, causing the fleas to drop from the animal in a partially stupefied condition.

\section{CHICKEN-LICE POWDERS.}

A large number of the so-called chicken-lice powders containing various amounts of naphthalene, tobacco powder, sulphur and lime, and occasionally small amounts of pyrethrum and phenols, were tested and found to be more or less effective against the dog flea, depending on the amounts of the active ingredients (naphthalene, nicotine, pyrethrum, and phenols) present and the fineness of the powders. Only 4 of the 21 powders of this type tested were found to be completely effective, although 10 of them killed from 75 to 95 per cent of the fleas.

\section{MISCELLANEOUS POWDERED MIXTURES.}

Five miscellaneous powders containing oils as the only active ingredient were tested and it was found that 18 per cent of sassafras oil was completely effective and that 10 per cent or less of several other oils was of no value. One powder composed of sawdust impregnated with 33 per cent of wood-tar creosote was of no value, this being due to the fact that the sawdust was so coarse that it did not penetrate to the skin.

\section{MISCELLANEOUS POWDERED MATERIALS.}

The following powdered materials were found to be more or less effective when used as dusts against the dog flea: Powdered cloves, naphthalene, paradichlorobenzene, and powdered sassafras bark. The results of experiments with them are given in Table IV.

TABLE IV.-Results of dusting tests with various powdered materials against the dog flea.

\begin{tabular}{|c|c|c|}
\hline Name. & $\begin{array}{l}\text { Number } \\
\text { of dogs } \\
\text { used. }\end{array}$ & $\begin{array}{l}\text { Per cent } \\
\text { of fleas } \\
\text { killed or } \\
\text { repelled. }\end{array}$ \\
\hline 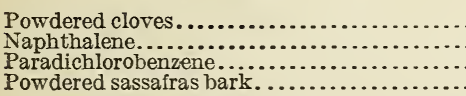 & $\begin{array}{l}4 \\
4 \\
2 \\
3\end{array}$ & $\begin{array}{r}100 \\
98-100 \\
100 \\
80-90\end{array}$ \\
\hline
\end{tabular}

The miscellaneous powdered materials tested and found to be of no value against the dog flea were allspice, angelica root, borax, boric acid, calcium sulphate, calcium fluorid, cornstarch, colocynth pulp, diatomaceous earth, eucalyptus leaves, hellebore, air-slaked lime, 
orris root, red pepper, quassia chips, road dust, sodium fluorid, sodium sulphite, flour of sulphur, refined sulphur, and sublimed sulphur.

It is of interest to note that sodium fluorid was found to be of no value against fleas, although it is very effective against chicken lice, it being considered by Bishopp and Wood ${ }^{13}$ as the best remedy for this pest.

Sulphur, which has often been recommended against fleas, was found in nine tests to be of no ralue.

\section{TOBACCO POWDERS.}

A series of nine tobacco powders containing from 0.11 to 4.56 per cent of nicotine was tested. The powders containing 1 per cent or more of nicotine were somewhat effective, but eren the highest percentage used did not kill all of the fleas. Since the tobacco powders sold on the market as insecticides rarely contain as much as 1 per cent of nicotine it can be readily seen that they can not be relied on for the control of this pest.

\section{SPRAYS.}

Table $V$ gives the results of tests with emulsified disinfectants used as sprays against the dog flea.

TABLE V.-Results of tests with emulsified disinfectants used as sprays against the dog flea.

\begin{tabular}{|c|c|c|c|c|c|c|c|}
\hline Test No. & Phennls. & Soap. & - Other actire ingredients. ${ }^{1}$ & $\begin{array}{c}\text { Inert } \\
\text { ingredi- } \\
\text { ents. }\end{array}$ & $\begin{array}{l}\text { Dilu- } \\
\text { tion. }\end{array}$ & $\begin{array}{l}\text { Number } \\
\text { of dogs } \\
\text { used. }\end{array}$ & $\begin{array}{l}\text { Fleas } \\
\text { killed or } \\
\text { repelled. }\end{array}$ \\
\hline $\begin{array}{l}12 . \\
13 . \\
4 .\end{array}$ & $\begin{array}{r}\text { Per cent. } \\
5.20 \\
50.21 \\
10.00 \\
17.20 \\
16.80 \\
16.90 \\
10.80 \\
10.80 \\
54.00 \\
12.30 \\
10.80 \\
30.10\end{array}$ & $\begin{array}{c}\text { Per ct. } \\
(?) \\
27.10 \\
(?) \\
23.40 \\
22.40 \\
22.40 \\
20.40 \\
20.10 \\
20.00 \\
32.40 \\
20.10 \\
(?)\end{array}$ & 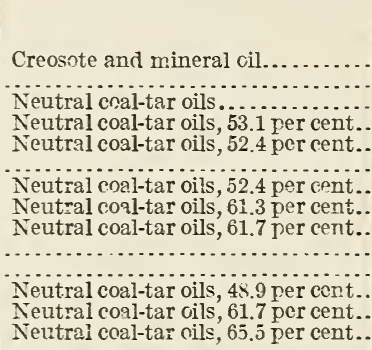 & $\begin{array}{c}\begin{array}{c}\text { Per cent } \\
\text { water. }\end{array} \\
\text { (?) } \\
(?) \\
6.3 \\
8.4 \\
6.6 \\
8.4 \\
7.5 \\
7.5 \\
26.1 \\
7.4 \\
8.4 \\
7.5 \\
4.1\end{array}$ & $\begin{array}{l}\text { None. } \\
1-50 \\
1-64 \\
1-64 \\
1-75 \\
1-75 \\
1-100 \\
1-128 \\
1-130 \\
1-200 \\
1-250 \\
1-260 \\
1-260 \\
1-264\end{array}$ & $\begin{array}{l}2 \\
1 \\
1 \\
1 \\
2 \\
2 \\
2 \\
1 \\
2 \\
1 \\
2 \\
2 \\
2 \\
1\end{array}$ & $\begin{array}{r}\text { Percent. } \\
100 \\
100 \\
100 \\
90 \\
0 \\
0 \\
0 \\
0 \\
0 \\
0 \\
0 \\
0 \\
0 \\
0\end{array}$ \\
\hline
\end{tabular}

1 An active ingredient is a material effective against dog feas when used at a proper dilution.

2 An emulsified coal-tar disinfectant.

This table shows that as a class the emulsified disinfectants are effectire against fleas when used as sprays at a dilution not greater than 1 to 64 ( 1 tablespoonful to a quart). This method of controlling fleas, however, is not a very satisfactory one since it is difficult to spray a dog properly and, in the case of dogs with long, thick hair, it is not easy to force the spray through it.

${ }^{13}$ Mites and Lice on Poultry, Farmers' Bulletin 801, U. S. Department of Agriculture. 
WASHES.

Table VI gives the results of tests with emulsified disinfectants used as washes against the dog flea.

TABLE VI.-Results of tests with sprays used as fumigants against the dog flea.

\begin{tabular}{|c|c|c|c|c|c|c|}
\hline $\begin{array}{l}\text { Test } \\
\text { No. }\end{array}$ & Phenols. & Other ingredients. & Method of treatment. & $\begin{array}{l}\text { Num- } \\
\text { ber of } \\
\text { dogs. }\end{array}$ & $\begin{array}{l}\text { Dura- } \\
\text { tion } \\
\text { of test. }\end{array}$ & $\begin{array}{l}\text { Killed or } \\
\text { repelled. }\end{array}$ \\
\hline $\begin{array}{l}1 . . \\
2 . .\end{array}$ & $\begin{array}{r}\text { Percent. } \\
16.16 \\
7.32 \\
5.00\end{array}$ & 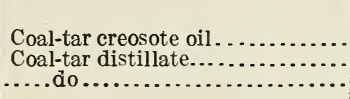 & $\begin{array}{l}\text { Confined in painted box... } \\
\text { Confined in sprayed box.. } \\
\text { Wrapped in sprayed blan- }\end{array}$ & $\begin{array}{l}1 \\
2 \\
2\end{array}$ & $\begin{array}{c}\text { Hours. } \\
1 \\
2^{\frac{1}{2}}\end{array}$ & $\begin{array}{r}\text { Per cent. } \\
100 \\
100 \\
100\end{array}$ \\
\hline & 4.15 & $\begin{array}{l}\text { Benzol, naphthalene, tar acids, } \\
\text { pyridine. }\end{array}$ & & 1 & & 100 \\
\hline & 2.17 & Light coal-tar oil... & ......do & 1 & 2 & 100 \\
\hline
\end{tabular}

These emulsified disinfectants proved to be very effective when used as washes at a dilution not to exceed 1 to 130 (2 tablespoonfuls to a gallon). Where dogs are regularly washed, as they should be, this method of treatment offers an easy and effective means for the control of fleas, since the emulsified coal-tar disinfectants are obtainable at almost any drug store and can very readily be added to the bath water.

\section{DIPS.}

Eight dipping tests were made with emulsified coal-tar disinfectants and, as might be expected, they were found to be effective at about the same strength as when used as washes, i. e., 1 part to 130 parts of water. At the rate of 1 to 200 in two tests only 20 per cent of the fleas were killed or repelled.

\section{LIQUIDS USED AS FUMIGANTS.}

Table VII gives the results of tests with liquids used as fumigants:

TABLE VII.-Results of tests with sprays used as fumigants against the dog flea.

\begin{tabular}{|c|c|c|c|c|c|c|}
\hline Test No. & Phenols. & Other ingredients. & Method of treatment. & $\begin{array}{c}\text { Number } \\
\text { of } \\
\text { dogs. }\end{array}$ & $\begin{array}{l}\text { Dura- } \\
\text { tion of } \\
\text { test. }\end{array}$ & $\begin{array}{c}\text { Killed } \\
\text { or } \\
\text { repelled. }\end{array}$ \\
\hline $1 \ldots$ & $\begin{array}{r}\text { Per cent. } \\
16.16\end{array}$ & Coal-tar cresote.. & Confined in painted & 1 & $\begin{array}{r}\text { Hours. } \\
1\end{array}$ & Per cent. \\
\hline 2. & 7.32 & Coal-tar oils.. & Confined in sprayed & 2 & $\frac{1}{2}$ & 100 \\
\hline 3. & 5.00 & $\begin{array}{l}\text { Creosote oils and carbon } \\
\text { disulphid. }\end{array}$ & $\begin{array}{l}\text { box. } \\
\text { Wrapped in sprayed } \\
\text { blanket. }\end{array}$ & 2 & 2 & 100 \\
\hline 4. & 4.15 & Benzol, naphthalene, nico- & .....do................. & 1 & & 100 \\
\hline 5. & 2.17 & Light coal-tar oil.. & .....do. & 1 & 2 & 100 \\
\hline
\end{tabular}


In tests Nos. 1 and 2 the interior of a box about 3 feet long, 2 feet wide, and 2 feet deep was thoroughly painted or sprayed, and a small dog was placed in the box, which was then covered with two or three thicknesses of burlap. This method of treatment produced a true fumigation, since the dogs in every case remained standing during the entire experiment. When the dogs were taken from the boxes examination showed no living fleas on them, and it is evident that the insects had been killed by the vapors arising from the sprays used. This view is supported by the results of a long series of tests of a similar nature, in which various oil preparations were found to be effective against chicken lice. (See p. 3-4.)

In tests Nos. 3, 4, and 5 the materials were lightly sprayed on a blanket or old sack, and this was tightly wrapped about the dog so that only the face and legs remained uncovered. This method of application gave, in addition to the fumigation effect, a very probable contact effect, since some of the oils would naturally pass from the blanket to the hair of the dog, and any fleas coming to the surface of the hair would come in contact with the sprayed blanket. This treatment was also very effective, as no living fleas were found on dogs that had been covered with the sprayed blankets for two hours.

\section{SUMMARY.}

1. Pyrethrum powder alone or when it formed not less than 50 per cent of a mixed powder was very effective, but pyrethrum stems were of no value.

2. Pure naphthalene was found to be effective if well rubbed into the hair.

3. Twenty-one lice powders were more or less effective, depending on the amount of active ingredients present and the fineness of the powder.

4. A powder containing 18 per cent of sassafras oil was effective, and powders containing 10 per cent or less of other oils were of no value.

5. Cloves, naphthalene, paradichlorobenzene, and sassafras bark were effective against fleas and 21 powdered substances were of no value.

6. Tobacco powders containing over 1 per cent of nicotine were of some value against fleas, but a powder containing as high as 4.56 per cent was not completely effective.

7. The emulsified disinfectants were found to be effective as sprays at the rate of 1 part to 64 parts of water and as washes and dips at 1 to 130 .

8. Several liquids used as fumigants were found to be effective against fleas. 
RECOMMENDATIONS.

A thorough dusting with good fresh pyrethrum powder is a simple and effective remedy against dog fleas. The powder can be easily applied by means of a hand dust gun, an old sugar shaker, or simply a tin can with small holes punched in the cover. It should be freely dusted over all parts of the body and well rubbed into the hair. If the dog is dusted in a shallow box or on an old blanket or a sheet of paper, the fleas, which will drop off in a stupefied condition, can be collected and burned.

Finely powdered naphthalene or paradichlorobenzene will be found effective if thoroughly rubbed into the hair and can be applied in the same manner as pyrethrum.

Where dogs are given regular baths, the addition of some of the common emulsified coal-tar creosote preparations generally sold as "emulsified coal-tar disinfectants," "coal-tar creosote dips," or "stock dips," or some emulsion containing cresols, phenols, or hydrocarbon oils, to the water at the rate of 1 to 130 (2 tablespoonfuls to the gallon) will be found very effective.

In considering the control of fleas it should be remembered that destroying those on the dog affords only a temporary relief, unless all breeding places are eliminated at the same time. ${ }^{14}$

If the dogs themselves are carefully dusted or washed and their kennels and sleeping places properly treated the flea problem will be solved.

14 A full discussion of methods for the control of flea breeding will be found in Farmers' Bulletin 897, U. S. Department of Agriculture, "Fleas and Their Control," by F. C. Bishopp. 
